\title{
Crown Ratio and Relative Spacing Relationships for Loblolly Pine Plantations
}

\author{
Dehai Zhao, Michael Kane, Bruce E. Borders \\ Warnell School of Forestry and Natural Resources, University of Georgia, Athens, USA \\ Email: zhaod@uga.edu
}

Received April 13 ${ }^{\text {th }}$, 2012; revised May 21 $1^{\text {st }}, 2012$; accepted June $6^{\text {th }}, 2012$

\begin{abstract}
Two loblolly pine (Pinus taeda L.) culture/density studies were established in 1995-1998 across the Lower Coastal Plain and Upper Coastal Plain/Piedmont regions of the southern USA. Each installation contains 12 plots of loblolly pine planted at six levels of density from 741 to 4448 trees/ha in combination with two levels of cultural intensity, operational and intensive. The data from 37 viable installations were used to evaluate the crown ratio and relative spacing relationship of loblolly pine plantations. The effects of planting density, site quality, and cultural intensity on the relationship were investigated with a nonlinear mixed-effects modeling approach. The crown ratio and relative spacing relationship is exceedingly predictable. When loblolly pine plantation stands reached the average live crown ratio of 0.40 , a critical point representing a generally acceptable level of tree vigor, the corresponding relative spacing index ranged from 0.11 to 0.20 , mainly depending on initial planting density. The information about the crown ratio and relative spacing relationship would be useful for selecting the best intensity and timing of thinning.
\end{abstract}

Keywords: Loblolly Pine; Intensive Culture; Planting Density; Live Crown Ratio; Relative Spacing Index

\section{Introduction}

Thinning as a forest management practice is employed in pine plantations for various reasons. For examples, the appropriate thinning regimes can reduce density-dependent mortality rates, increase individual tree growth rates, improve product assortment ratios, and enhance spatial and structural uniformity (Newton, 2009). Practically, there are several indicators of stand conditions that can aid in determining thinning regimes, such as live crown ratio $(C R)$, relative spacing index $(R S)$, and relative stand density $(R D)$. $C R$ is defined as the height of the live crown (the part of the tree with live branches) divided by the total height of the tree. $C R$ is a common indicator of tree vigor (Smith, 1988) and used to determine the timing of and potential response of thinning (Bennett, 1955; Dyer \& Burkhart, 1987; Long, 1985). Tree vigor and normal rate of diameter growth are maintained as long as $C R$ is 0.40 or greater (Harrington, 2000; Smith, 1988), and ideally a thinning treatment should be scheduled soon after average $C R$ drops below 0.50 (Harrington, 2000). CR, also as an indirect measure of a tree's photosynthetic capacity and a measure of stand density, is used as a predictor variable in many existing forest growth and yield models (Leites et al., 2009; Monserud \& Sterba, 1996).

$R S$ is defined as the ratio of the average distance between trees to the average dominant height of stand. With square spacing the ratio is described as $R S=\sqrt{10000 / N} / H D$, where $N$ is the number of trees per hectare and $H D$ is average dominant height (m). RS includes the number of trees and incorporates both site quality and age through dominant height; thus, it has been proposed as a useful measure of stand density for developing thinning specifications for managed plantations (Wilson, 1946, 1979). Thinning schedules can be determined by setting proper upper and lower bounds of RS. The desired upper and lower $R S$ bounds for loblolly pine (Pinus taeda L.) plantations were proposed at 0.3 and 0.2 , respectively (Zhao et al., 2010).

$R D$ is the ratio between stand density index (SDI) and maximum SDI. For loblolly pine the maximum SDI is 450 . Stands begin to undergo density-related mortality (self-thinning) at 0.50 - 0.55 of maximum SDI (Dean \& Baldwin, 1993; Drew \& Flewelling, 1979). Therefore, thinning should be scheduled when $R D$ reaches 0.45 (Dean \& Baldwin, 1993; Harrington, 2000). Because these three criteria ( $C R, R S$ and $R D$ ) could be considered for selecting the best intensity and timing of thinning, there should be some predictable relationships among them.

In general, both $C R$ and $R S$ decline over time, but they follow different patterns. $C R$ follows an inverse sigmoidal curve. In early years, the $C R$ remains very high, with live branches being retained over nearly 100 percent of stem. As the stand enters the period of total height rapid development the $C R$ decreases rapidly. Then as the stand grows older and the height rate is slowing down, the $C R$ gradually levels at a minimum value. The change of $R S$ over time follows a typical inverse-J trend, which is dependent on the relationship between height increment and mortality (Parker, 1978). In early years, the RS changes are due primarily to height growth. With crown closure the increasing mortality rate plays a more important role, and $R S$ changes are slowing down. Then $R S$ remains constant with a minimum value. For $R D$, it increases and approaches toward 1 as the stand develops, following a sigmoidal curve. There is a negative relationship between average $C R$ and $R D$ (Long, 1985). Dean (1999) found that average $C R$ decreases linearly with increases in $R D$ for loblolly pine plantations in the West Gulf. He developed a linear model for the $C R$ and $R D$ relationship and used to manage quality objectives. For the $C R$ and $R S$, there is relatively little research on their relationship, except 
for some work of Kanazawa et al. (1985, 1990).

Previous studies (Harrison \& Kane, 2008; Zhao et al., 2008) indicated that the $C R$ declining trend over time is significantly influenced by initial density and management intensity. The $C R$ decrease rate increases with increasing initial density and management intensity. Tree $C R$ models for estimating $C R$ from tree and/or stand attributes have been developed for several species (Dyer \& Burkhart, 1987; Hasenauer \& Monserud, 1996; Temesgen et al., 2005), but there is no model developed for directly describing the $C R$ change through time. The $R S$ development through time has been modeled for loblolly pine plantations in the southern United States (Zhao et al., 2010). The resulting models indicated significant effects of initial density, site index and management intensity on the $R S$ trend. The intensively managed plots have lower $C R$ and $R S$ than operationally managed plots planted at the same density; with the same management intensity, both the $C R$ and $R S$ decline with increasing initial density (Zhao et al., 2009, 2010). Therefore, if there is a predictable relationship between $C R$ and $R S$, this relationship is expected to be influenced by initial density, site index and management intensity.

With data from two loblolly pine culture and density studies across the southeastern United States, the objective of the present study is to test the hypothesis that there is a predictable relationship between the $C R$ and $R S$. Moreover, the effects of initial planting density, site quality, and management intensity on this relationship are investigated with a nonlinear mixedeffects modeling approach.

\section{Materials and Methods}

\section{Study Description}

The data came from two well-designed loblolly pine culture and density studies initiated by the Plantation Management Research Cooperative (PMRC) of the University of Georgia. The Lower Coastal Plain (LCP) Culture/Density Study was established in 1995/96, with seventeen installations in Georgia, Florida and South Carolina across five broad soil groups. The Piedmont and Upper Coastal Plain (PUCP) Culture/Density study was established in 1997/98, with twenty-three installations in Georgia, Alabama, Florida, Mississippi and South Carolina, stratified over seven broad soil classes.

In both Culture/Density studies, site preparation and subsequent silvicultural treatments were designed to represent two levels of management intensity: operational and intensive culture. In the LCP study, the operational treatment consisted of bedding in the spring followed by a fall banded chemical site preparation; the intensive cultural treatment included bedding in the spring followed by a fall broadcast chemical site preparation. The intensive cultural treatment plots also received tip moth control through the first two growing seasons and repeated herbicide applications to achieve complete vegetation control throughout their rotation. At planting, $561 \mathrm{~kg} / \mathrm{ha}$ of 1010-10 fertilizer was applied on all plots. The operation treatment plots were fertilized with the equivalent of $224 \mathrm{~kg} / \mathrm{ha}$ of $\mathrm{N}$ and $28 \mathrm{~kg} / \mathrm{ha}$ of $\mathrm{P}$ in the spring of the eighth and twelfth growing seasons. The intensive cultural treatment plots also received $673 \mathrm{~kg} / \mathrm{ha}$ of $10-10-10$ plus micronutrients and $131 \mathrm{~kg} / \mathrm{ha}$ of $\mathrm{NH}_{4} \mathrm{NO}_{3}$ in the spring of the third growing season, $131 \mathrm{~kg} / \mathrm{ha}$ $\mathrm{NH}_{4} \mathrm{NO}_{3}$ in the spring of the fourth growing season, $336 \mathrm{~kg} / \mathrm{ha}$ $\mathrm{NH}_{4} \mathrm{NO}_{3}$ in the spring of the sixth growing season, and 224 $\mathrm{kg} / \mathrm{ha}$ of $\mathrm{N}$ and $28 \mathrm{~kg} / \mathrm{ha}$ of $\mathrm{P}$ in the spring of the eighth, tenth, and twelfth growing seasons.

In the PUCP study, any tillage treatments included in site preparation were carried out on all treatment plots. Both the operational and intensive treatments included a broadcast chemical site preparation. The operational treatment included a firstyear banded weed control. The intensive cultural treatment plots received additional herbicide treatments to keep them as completely free of competing vegetation as possible throughout their rotation and received tip moth control through the first two growing seasons. The same fertilizer treatments in the operational and intensive cultural treatment regimes as the LCP study were applied.

Within both the intensive and operational treatments, six loblolly pine subplots with densities of 741, 1483, 2224, 2965, 3706 and 4448 trees/ha were randomly located and established in each installation. To ensure the targeted initial density, each planting spot was double-planted and reduced to a single surviving seedling after the first growing season. For detailed information on these two studies such as soils and treatments carried out for each management level, please refer to Harrison and Kane (2008) and Zhao et al. (2008, 2010).

Beginning after the second growing season, biennial measurements of diameters at breast height (DBH) for all trees and heights $(\mathrm{H})$ on every other tree were made. Heights to the base of the live crown were measured on all trees that were measured for total height. Total heights of unmeasured trees were estimated using a height-diameter equation, $\ln (H)=b_{0}+b_{1} / D B H$, fitted to each plot at each measurement age. A tree was considered a dominant tree if it was in the upper 50percent of diameters on the plot. Mean live crown ratio was calculated by plot from trees with height measurements, and relative spacing index was also calculated by plot.

Base age 25 years site index values were estimated for each installation using the dominant height of the operational treatment plot with 1483 trees/ha planting density at the age of the most recent measurement. Site index was calculated using the site index equations developed by Borders et al. (2004) for second rotation loblolly pine plantations. Site indices ranged from 22.8 to $31.3 \mathrm{~m}$ for the LCP Culture/Density Study and from 22.4 to $28.1 \mathrm{~m}$ for the PUCP Culture/Density Study.

After 12 growth seasons 14 of the original 17 installations in the LCP culture/density study were viable; and all 23 installations in the PUCP culture/density study remained after 10 growth seasons. Data from these active installations were used for the analysis reported.

\section{Model Development}

Plot examination of the $C R$ versus $R S$ indicated that $C R$ is positively correlated with $R S$. While $C R$ more closely approaches 1 in early ages, the $R S$ is larger. With stand development both the $R S$ and $C R$ become smaller, approaching to their different minimum values. To constrain $C R$ predictions between 0 and 1 , the following general equation was used to describe the relationship between the $C R$ and $R S$ :

$$
C R=R S^{\phi_{2}} /\left(\phi_{1}+R S^{\phi_{2}}\right)
$$

where $\phi_{1}$ and $\phi_{2}$ are the parameters.

Preliminary analysis indicated that both parameters $\phi_{1}$ and $\phi_{2}$ varied across installations and plots. These between-installation and between-plot variations may be accounted in the 
model by taking the parameters as mixed effects. Further evaluation that the parameters $\phi_{1}$ and $\phi_{2}$ had some linear relationships with initial planting density $\left(N_{0}\right.$, trees/ha), management intensity (TRT, a dummy variable indicating the management intensity: $T R T=1$ for intensive culture and $T R T=0$ for operational culture), and/or site index (SI, m). Thus, the effects of planting density, site index and management intensity were taken as fixed to both parameters $\phi_{1}$ and $\phi_{2}$. After introducing fixed-effects of planting density, management intensity, especially of site index into two parameters, only the plot effects are considered random, denoted as $\left\{b_{i}\right\}$, and included in the parameters. Let $C R_{i j}$ and $R S_{i j}$ denote crown ratio and relative spacing at occasion $j$ for the plot $i$; $\varepsilon_{i j}$ denotes the corresponding residual for $C R_{i j}$. Thus, the mixed effects model is applied to individual plot as

$$
\begin{aligned}
& C R_{i j}=\frac{R S_{i j}^{\phi, 2}}{\phi_{i, 1}+R S_{i j}^{\phi, 2}}+\varepsilon_{i j} \\
& \phi_{i, 1}=\alpha_{0}+\alpha_{1} S I+\alpha_{2} T R T+\alpha_{3}\left(N_{0} / 100\right)+b_{i}^{(1)} \\
& \phi_{i, 2}=\beta_{0}+\beta_{1} S I+\beta_{2} T R T+\beta_{3}\left(N_{0} / 100\right)+b_{i}^{(2)} \\
& \left(\begin{array}{l}
b_{i}^{(1)} \\
b_{i}^{(2)}
\end{array}\right) \sim N(0, \psi), \quad \varepsilon_{i j} \sim N\left(0, \sigma_{e}^{2}\right) .
\end{aligned}
$$

The random-effects terms and their corresponding appropriate variance-covariance matrix $\psi$ in (2) are further identified. Then, based on the final nature of random effects and structure in (2), the effects of planting density, site index and management intensity on the $C R$ and $R S$ relationship were tested in terms of parameters $\phi_{1}$ and $\phi_{2}$ with the likelihood ratio test (LRT). The model fit, model comparison, and tests were performed using the NLME library by Pinheiro and Bates (2000) for S-plus software, and separately for the data from the LCP and PUCP Culture/Density studies.

\section{Results and Discussion}

In the $C R$-RS models for both the LCP and PUCP regions, after including the fixed-effects of planting density, site index and management intensity into both the parameters $\phi_{1}$ and $\phi_{2}$, the plot random-effects was no significant on the parameter $\phi_{1}$, but still significant on the parameter $\phi_{2}$. Therefore, only the parameter $\phi_{2}$ was taken as mixed effects. The random-effects variance-covariance matrix $\psi$ was changed to $\sigma_{\phi 2}^{2}$, that is, $\left\{b_{2}^{(2)}\right\} \sim N\left(0, \sigma_{\phi 2}^{2}\right)$. SI was not a significant predictor of the parameter $\phi_{1}$ for either of the studies at $\alpha=0.05$. Planting density was significant at $\alpha=0.05$ in terms of parameter $\phi_{1}$ for the PUCP Culture/Density study, but no significant for the LCP Culture/Density study. In terms of parameter $\phi_{2}$, all the effects of planting density, site index and management intensity were significant at $\alpha=0.05$.

After excluding non-significant covariates from the model, we determined and refitted the final model. Parameter estimates of the final model for each of the two culture/density studies are given in Table 1. The CR-RS relationship for loblolly pine plantations was described by

$$
\begin{aligned}
\hat{\phi}_{1} & =0.04223-0.01922 \cdot T R T \\
\hat{\phi}_{2} & =2.50108-0.01347 \cdot S I+0.34832 \cdot T R T \\
& -0.01033 \cdot\left(N_{0} / 100\right)
\end{aligned}
$$

for the LCP region; and

$$
\begin{aligned}
\hat{\phi}_{1}= & 0.03602-0.01886 \cdot T R T-0.00015 \cdot\left(N_{0} / 100\right) \\
\hat{\phi}_{2}= & 3.43792-0.04503 \cdot S I \\
& +0.48737 \cdot T R T-0.00786 \cdot\left(N_{0} / 100\right)
\end{aligned}
$$

for the PUCP regions. The augmented prediction plots indicated that the final models describe the $C R-R S$ relationship of individual loblolly pine plots well, and the residual plots did not indicate any serious deficiencies in the final models.

As stands develop, both the $C R$ and $R S$ decrease. Although the changes of $C R$ and $R S$ over time follow different patternsan inverse sigmoidal curve and a typical inverse-J curve, respectively, the positive relationship between $C R$ and $R S$ can still be described by Model (1). The resulting $C R-R S$ models for loblolly pine plantations in the LCP and PUCP regions, Models

\begin{tabular}{|c|c|c|c|c|c|c|c|}
\hline & \multirow{2}{*}{ Parameter } & \multicolumn{3}{|c|}{ LCP } & \multicolumn{3}{|c|}{ PUCP } \\
\hline & & Estimates & $\mathrm{SE}$ & $p$-value & Estimates & $\mathrm{SE}$ & $p$-value \\
\hline \multirow[t]{3}{*}{$\phi_{1}$} & $\alpha_{0}$ & 0.04223 & 0.00225 & $<0.0001$ & 0.03602 & 0.00216 & $<0.0001$ \\
\hline & $\alpha_{2}(T R T)$ & -0.01922 & 0.00257 & $<0.0001$ & -0.01886 & 0.00202 & $<0.0001$ \\
\hline & $\alpha_{3}\left(N_{0} / 100\right)$ & & & & -0.00015 & 0.00003 & $<0.0001$ \\
\hline \multirow[t]{6}{*}{$\phi_{2}$} & $\beta_{0}$ & 2.50108 & 0.10578 & $<0.0001$ & 3.43792 & 0.13017 & $<0.0001$ \\
\hline & $\beta_{1}(\mathrm{~S})$ & -0.01347 & 0.00345 & 0.0001 & -0.04503 & 0.00425 & $<0.0001$ \\
\hline & $\beta_{2}(T R T)$ & 0.34832 & 0.04776 & $<0.0001$ & 0.48737 & 0.05813 & $<0.0001$ \\
\hline & $\beta_{3}\left(N_{0} / 100\right)$ & -0.01033 & 0.00061 & $<0.0001$ & -0.00786 & 0.00131 & $<0.0001$ \\
\hline & $\sigma_{\phi 2}$ & 0.06913 & & & 0.06106 & & \\
\hline & $\sigma_{e}$ & 0.04599 & & & 0.05113 & & \\
\hline
\end{tabular}
(3) and (4), indicated that the relationship between $C R$ and $R S$ is exceedingly predictable.

Our results showed that initial planting density significantly affected the $C R$ and $R S$ relationship for both regions (Figure 1). In general, stands planted at higher density will have a larger $C R$ than stands planted at lower density when both reach a

\section{Table 1.}

Maximum likelihood estimates of the parameter, standard errors (SE), and p-values from the final mixed-effects crown ratio—relative spacing index models fitted for the culture/density studies in the Lower Coastal Plain (LCP), and Piedmont/Upper Coastal Plain (PUCP) regions, respectively. 
specific $R S$. For loblolly pine stands on site index of $24 \mathrm{~m}$ and with the intensive management regime, when their $R S$ decreases to 0.3 , as planting density increases from 741 to 4448 trees/ha, the $C R$ increases from 0.69 to 0.78 in the LCP and from 0.70 to 0.84 in the PUCP, respectively. When the $R S$ reaches 0.2 the $C R$ ranges from 0.46 to 0.61 in the LCP, and from 0.43 to 0.66 in the PUCP, respectively.

In terms of parameter in the $C R$-RS model, site index was significant for both regions. For a given planting density and management intensity, however, the effect of site index on overall $C R-R S$ relationship is much smaller in the LCP than in the PUCP (Figure 2). In terms of both parameters $\phi_{1}$ and $\phi_{2}$, the effect of management intensity was significant for both the LCP and PUCP. However, further examination of overall $C R$ $R S$ relationship suggested that, for a given site index and initial density, management intensity strongly affect loblolly pine
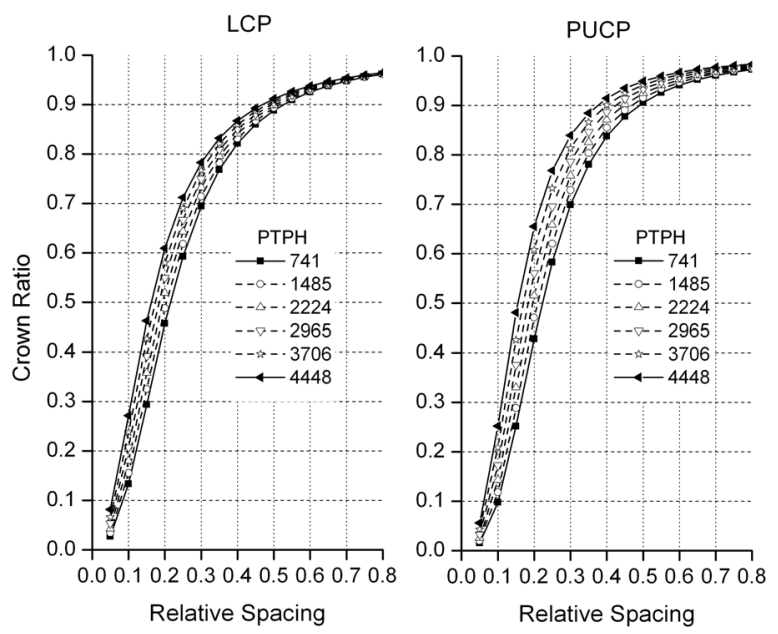

Figure 1.

Crown ratio and relative spacing relationship for loblolly pine stands with six levels of initial planting density (trees/ha) for site index 24 $\mathrm{m}$ under the intensive management regime in the Lower Coastal Plain (LCP) and Piedmont/Upper Coastal Plain (PUCP) regions.
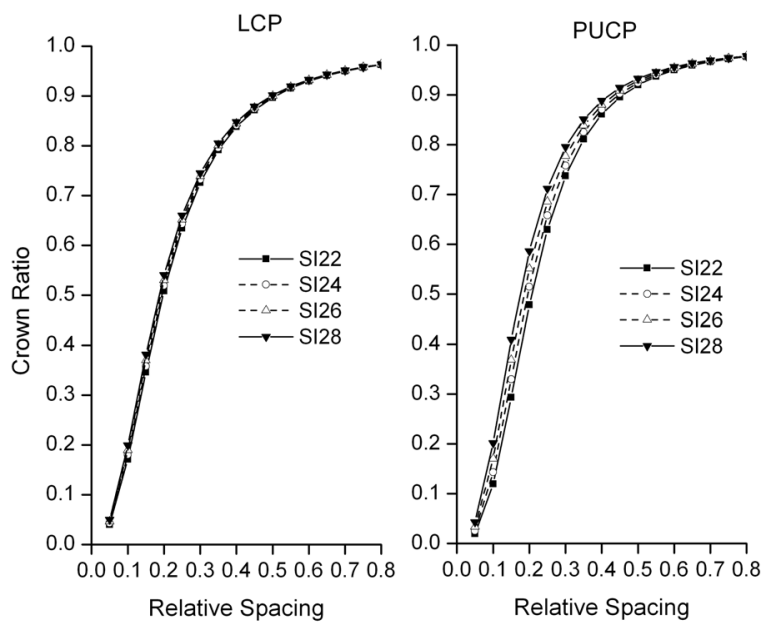

Figure 2.

Crown ratio and relative spacing relationship for loblolly pine stands for four levels of site index and initial planting density of 2224 trees/ ha under the intensive management regime in the Lower Coastal Plain (LCP) and Piedmont/Upper Coastal Plain (PUCP) regions.
$C R$ - $R S$ relationship before the $R S$ decreases to 0.2 or before the $C R$ reaches 0.5 . During that period, intensively-managed plots will have larger $C R$ than operational plots when they reach the same value of $R S$. After that period, the $C R-R S$ relationship is less affected by management intensity (Figure 3 and Table 2).

Given the average $C R$, the $R S$ can be calculated with the model after simple algebraic manipulation, i.e.,

$$
R S=\left[\left(\hat{\phi}_{1} C R /(1-C R)\right)\right]^{1 / \hat{\phi}_{2}} .
$$

When loblolly pine plantations reach average $C R$ of 0.40 , a generally acceptable level of tree vigor for numerous conifers (Long 1985; Smith 1988), our models suggested that the RS value will range from 0.11 to 0.20 , mainly depending on initial planting density (Table 2). For southern pines, Demers et al. (2005) believed that optimum growth and vigor are maintained before the average $C R$ falls below 0.33 . Based on our models, the $R S$ corresponding to $0.33 C R$ for loblolly pines will range from 0.10 to 0.18 . Harrington (2000) suggested that ideally a thinning treatment should be scheduled soon after average $C R$ drops below 0.50 for loblolly pine. The $R S$ corresponding to $0.50 C R$ for loblolly pines ranges from 0.14 to 0.25 .

According to Dean's model for the $C R-R D$ relationship for loblolly pines in the West Gulf Dean (Dean, 1999), the $R D$ corresponding to 0.40 average $C R$ is 0.63 . Using data from our loblolly pine culture and density studies, the negative $C R-R D$ relationship is described by the equation: $C R=0.9751-0.6623 R D$. Furthermore, this relationship is not influenced by planting density, site index, and management intensity. Based on this model, corresponding to average $C R$ of 0.4 for loblolly pines in the southern US the $R D$ is 0.87 , and corresponding to average $C R$ of 0.5 the $R D$ is 0.72 . It was suggested that thinning should be scheduled for loblolly pine plantations when the $R D$ reaches 0.45 (Dean \& Baldwin 1993; Harrington, 2000), which corresponds to $0.68 C R$. It is obvious that simultaneously considering the $C R$ and $R D$ as thinning triggers may result in different decision on timing of thinning.

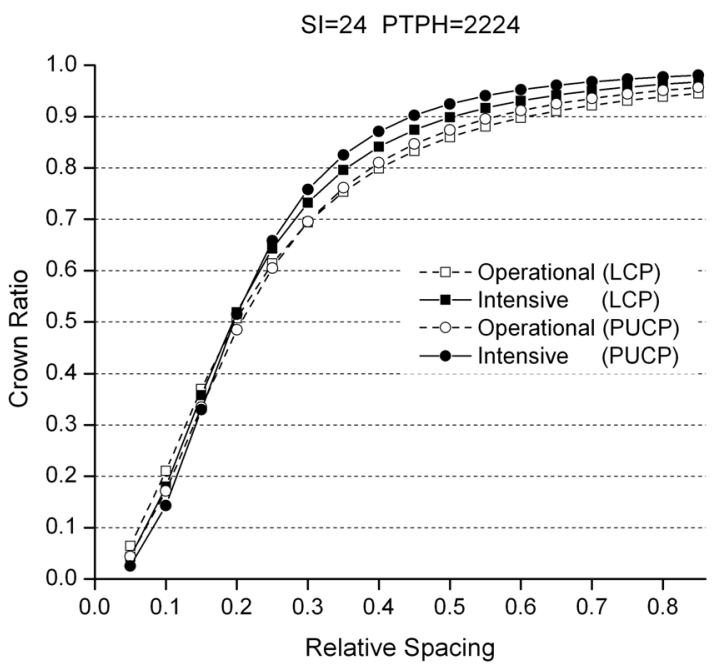

Figure 3.

Crown ratio and relative spacing relationship for loblolly pine stands for two levels of management intensity (operational and intensive) in the Lower Coastal Plain (LCP) and Piedmont/Upper Coastal Plain (PUCP) regions for 2224 trees/ha planting density and $24 \mathrm{~m}$ site index. 
Table 2.

Estimated relative spacing when loblolly pine plantations have a crown ratio of 0.40 by physiographic region, planting density, management intensity, and site quality.

\begin{tabular}{|c|c|c|c|c|c|c|c|c|c|}
\hline \multirow{2}{*}{ Region } & \multirow{2}{*}{ Planting Density (trees/ha) } & \multicolumn{4}{|c|}{ Operational } & \multicolumn{4}{|c|}{ Intensive } \\
\hline & & $\mathrm{SI}=22$ & $\mathrm{SI}=24$ & $\mathrm{SI}=26$ & $\mathrm{SI}=28$ & $\mathrm{SI}=22$ & $\mathrm{SI}=24$ & $\mathrm{SI}=26$ & $\mathrm{SI}=28$ \\
\hline \multirow[t]{6}{*}{ Lower Coastal Plain } & 741 & 0.19 & 0.18 & 0.18 & 0.17 & 0.19 & 0.18 & 0.18 & 0.17 \\
\hline & 1485 & 0.18 & 0.17 & 0.17 & 0.16 & 0.18 & 0.17 & 0.17 & 0.17 \\
\hline & 2224 & 0.16 & 0.16 & 0.16 & 0.15 & 0.17 & 0.16 & 0.16 & 0.16 \\
\hline & 2965 & 0.15 & 0.15 & 0.14 & 0.14 & 0.16 & 0.15 & 0.15 & 0.15 \\
\hline & 3706 & 0.14 & 0.14 & 0.13 & 0.13 & 0.15 & 0.14 & 0.14 & 0.14 \\
\hline & 4448 & 0.13 & 0.13 & 0.12 & 0.12 & 0.14 & 0.13 & 0.13 & 0.13 \\
\hline \multirow[t]{6}{*}{ Piedmont/Upper Coastal Plain } & 741 & 0.20 & 0.19 & 0.18 & 0.17 & 0.20 & 0.19 & 0.18 & 0.17 \\
\hline & 1485 & 0.19 & 0.18 & 0.17 & 0.16 & 0.19 & 0.18 & 0.17 & 0.16 \\
\hline & 2224 & 0.18 & 0.17 & 0.16 & 0.15 & 0.18 & 0.17 & 0.16 & 0.15 \\
\hline & 2965 & 0.17 & 0.16 & 0.15 & 0.13 & 0.17 & 0.16 & 0.15 & 0.14 \\
\hline & 3706 & 0.16 & 0.15 & 0.14 & 0.12 & 0.15 & 0.14 & 0.13 & 0.12 \\
\hline & 4448 & 0.15 & 0.14 & 0.13 & 0.11 & 0.14 & 0.13 & 0.12 & 0.11 \\
\hline
\end{tabular}

When calculating the $R D$ for loblolly pines, the maximum SDI is accepted as 450 . However, the SDI of some plots in our culture and density studies was actually greater than 450 . Therefore, when the $R D$ is considered as one of thinning criteria, choosing the maximum SDI is important.

In summary, there is a predictable relationship between live crown ratio and relative spacing index for loblolly pine plantations. This relationship is affected by initial planning density, site quality, management intensity, and physiographic region.

\section{Acknowledgements}

This study was sponsored by the Plantation Management Research Cooperative (PMRC) at the University of Georgia's Warnell School of Forestry and Natural Resources.

\section{REFERENCES}

Bennett, F. (1955). The effect of pruning on the height and diameter growth of planted slash pine. Journal of Forestry, 53, 636-638.

Dean, T. J. (1999). Using live-crown ratio to control wood quality: An example of quantitative silviculture. In J. D. Haywood (Ed.), Proceedings of the Tenth Biennial Southern Silvicultural Research Conference (pp. 511-514). Asheville, NC: US Forest Service Southern Research Station.

Dean, T. J., \& Baldwin, V. C. Jr. (1993). Using a density-management diagram to develop thinning schedules for loblolly pine plantations. Juneau, AK: USDA Forest Service.

Dean, T. J., \& Baldwin. V. C. Jr. (1996). Growth in loblolly pine plan-tations as a function of stand density and canopy properties. Forest Ecology and Management, 82, 49-58. doi:10.1016/0378-1127(95)03694-6

Demers, C., Long, A., \& Nowak, J. (2005). Thinning southern pinesA key to greater returns. Gainesville, FL: University of Florida, Institute of Food and Agricultural Science, Florida Cooperative Extension Service.

Drew, T. J., \& Flewelling, J. W. (1979). Stand density management: An alternative approach and its application to Douglas-fir plantations. Forest Science, 25, 518-532.

Dyer, M. E., \& Burkhart, H. E. (1987). Compatible crown ratio and crown height models. Canadian Journal of Forest Research, 17, 572-574. doi:10.1139/x87-096

Harrington, T. B. (2000). Silvicultural approaches for thinning southern pines: Method, intensity, and timing. Macon, GA: Georgia Forestry Commission.

Harrison, W. M., \& Kane, M. (2008). PMRC Coastal Plain culture/ density study: Age 12 analysis. Athens, GA: University of Georgia, Warnell School of Forestry and Natural Resources.

Hasenauer, H., \& Monserud, R. A. (1996). A crown ratio model for Austrian forests. Forest Ecology and Management, 84, 49-60. doi:10.1016/0378-1127(96)03768-1

Kanazawa, Y., Kiyono, Y., \& Fujimori, T. (1985). Crown development and stem growth in relationship to stand density in even-aged pure stands (II): Clear-length model of Crytomeria japonica stands as a function of stand density and tree height. Journal of the Japanese Forest Society, 67, 391-397.

Kanazawa, Y., Kiyono, Y., \& Fujimori, T. (1990). Relationship between canopy depth and other dimensions of coastal Pinus thunbergii Parlat. forests in Japan. Tree Physiology, 7, 317-327.

Leites, L. P., Robinson, A. P., \& Crookston, N. L. (2009). Accuracy and equivalence testing of crown ratio models and assessment of their impact on diameter growth and basal area increment predictions of two variants of the Forest Vegetation Simulator. Canadian Journal of Forest Research, 39, 655-665. doi:10.1139/X08-205

Long, J. N. (1985). A practical approach to density management. Forestry Chronicle, 61, 23-17.

Monserud, R. A., \& Sterba, H. (1996). A basal area increment model for individual trees growing in even- and uneven-aged forest stands in Austria. Forest Ecology and Management, 80, 57-80. doi:10.1016/0378-1127(95)03638-5

Newton, P. F. (2009). Development of an integrated decision-support model for density management within jack pine stand-types. Ecological Modelling, 220, 3301-3324. doi:10.1016/j.ecolmodel.2009.07.025

Parker, R. C. (1978). Investigations into the limits of stand density. Ph.D. Thesis, Athens, GA: University of Georgia.

Pinheiro, J. C., \& Bates, D. M. (2000). Mixed-effects models in S and 
D. H. ZHAO ET AL.

S-PLUS. New York: Springer-Verlag. doi:10.1007/978-1-4419-0318-1

Smith, D. M. (1988). The practice of silviculture. New York: John Wiley.

Temesgen, H., LeMay, V., \& Mitchell, S. J. (2005). Tree crown ratio models for multi-species and multi-layered stands of southeastern British Columbia. Forestry Chronicle, 81, 133-141.

Wilson, F. G. (1946). Numerical expression of stocking in term of height. Journal of Forestry, 44, 758-761.
Wilson, F.G. 1979. Thinning as an orderly discipline: A graphic spacing schedule for red pine. Journal of Forestry, 77, 483-486.

Zhao, D., Kane, M., \& Harrison, W. M. (2008). SAGS culture/density study: Results through age 10. Athens, GA: University of Georgia, Warnell School of Forestry and Natural Resources.

Zhao, D., Kane, M., \& Borders, E. B. (2010). Development and applications of the relative spacing model for loblolly pine plantations. Forest Ecology and Management, 259, 1922-1929.

doi:10.1016/j.foreco.2010.02.003 